\title{
C3, factor B, alpha-1-antitrypsin in neonatal septicaemia with sclerema
}

\author{
B PELET \\ Service de Pédiatrie, Centre Hospitalier Universitaire Vaudois, Lausanne, Switzerland
}

SUMMARY $\mathrm{C} 3$, factor B, and $\alpha$-1-antitrypsin were determined in newborn infants with septicaemia and sclerema, associated with suspected infections, $\mathrm{ABO}$ or $\mathrm{Rh}$ incompatibility, and hyperbilirubinaemia of unknown origin, during and after treatment with exchange transfusion. Activation products from $\mathrm{C} 3$ and factor $\mathrm{B}$, the clearance of the transfused $\mathrm{C} 3$, and its synthesis by the recipient were determined also. Infected newborn infants had low levels of C3 and factor B, but a normal amount of $\alpha$-1-antitrypsin. Exchange transfusion lowered the level of $\alpha-1$-antitrypsin and briefly corrected the low level of $\mathrm{C} 3$ and factor B. Activation products were formed only exceptionally. As synthesis of $\mathrm{C} 3$ is very active, a defective activation of complement pathway linked to an abnormal distribution in extravascular pool is postulated.

We reported the presence of an opsonic defect in neonatal sepsis previously. Such a defect can be corrected in vitro by incubating the patient's granulocytes with normal serum. ${ }^{1}$ The underlying mechanism for the diminished opsonisation is poorly understood. In a pilot study concerning a newborn baby with pneumococcal sepsis, we observed a profound diminution of the third complement component (C3) and properdin factor B. However, exchange transfusions in this and in other newborn infants with sepsis corrected these abnormalities. In the present study we wished to find out whether the opsonic defect was related directly to an abnormality in the synthesis of the complement component or was due to accelerated consimption. Measurements of $\mathrm{C} 3$ phenotypes were used to study the synthesis and consumption of complement factors before and after exchange transfusion. In addition we studied the role of $\alpha$-1-antitrypsin, a potential blocker of various kinins, in recovery from neonatal sepsis.

\section{Material and methods}

12 premature and 5 term babies with neonatal sepsis or suspected infections were exchangetransfused with $180 \mathrm{ml} / \mathrm{kg}$ fresh ( $<60$ hours old) citrated blood. 11 septic newborn babies, 10 of whom had sclerema neonatorum too, received 33 exchange transfusions. The causative organisms in these patients were Escherichia coli, Klebsiella pneumoniae, Haemophilus influenzae, Proteus mirabilis, Staphylococcus aureus, Streptococcus pneumoniae type III, and Streptococcus haemolyticus B. Six newborn babies with suspected infection received 8 exchange transfusions; 15 newborn babies (4 premature and 11 term) were given 17 transfusions for hyperbilirubinaemia of unknown origin, or $\mathrm{Rh}$ or ABO incompatibility, and were used as a control group.

Blood samples were obtained from the donors shortly before the transfusion, and from the patient at the beginning, at one-third or one-half, at two-thirds of the transfusion volume, at the end of the transfusion, and at 1, 3, 6, and 12 hours after it. Clotting was allowed to proceed at $4^{\circ} \mathrm{C}$ and aliquots of serum were immediately frozen at $-70^{\circ} \mathrm{C}$ Samples of $0.5 \mathrm{ml}$ blood were obtained from the. unbilical artery or from a heel prick.

Quantitative determinations and certain other electrophoretic studies were run on an LKB multiphor system at $4^{\circ} \mathrm{C}$ in the room (LKB-Produkter AB S-161-25 Bromma 1. Sweden). Plates were cooled at $1{ }^{\circ} \mathrm{C}$ by a Haake thermostat during the run (Haake Inc., Saddle Brook, NJ 07662 USA). Current was supplied by an LKB 2103 power supply. Alpha-1antitrypsin concentrations were measured by radial immunodiffusion $^{2}$ using a commercial specific antiserum (Atlantic Antibody Corporation, Westbrook, Maine, USA). A reference serum was provided by Behring and Co (3550 Marburg (Lahn) Germany). C3 level was determined by electroimmunodiffusion, ${ }^{3}$ using a specific antibody in $1 \%$ agarose in $0.05 \mathrm{~mol} / \mathrm{l}$ veronal and $0.009 \mathrm{~mol} / \mathrm{l}$ EDTA, pH 8.6 buffer. A pool of 12 fresh human sera, frozen in aliquots at $-70^{\circ} \mathrm{C}$, was used as a reference standard. 

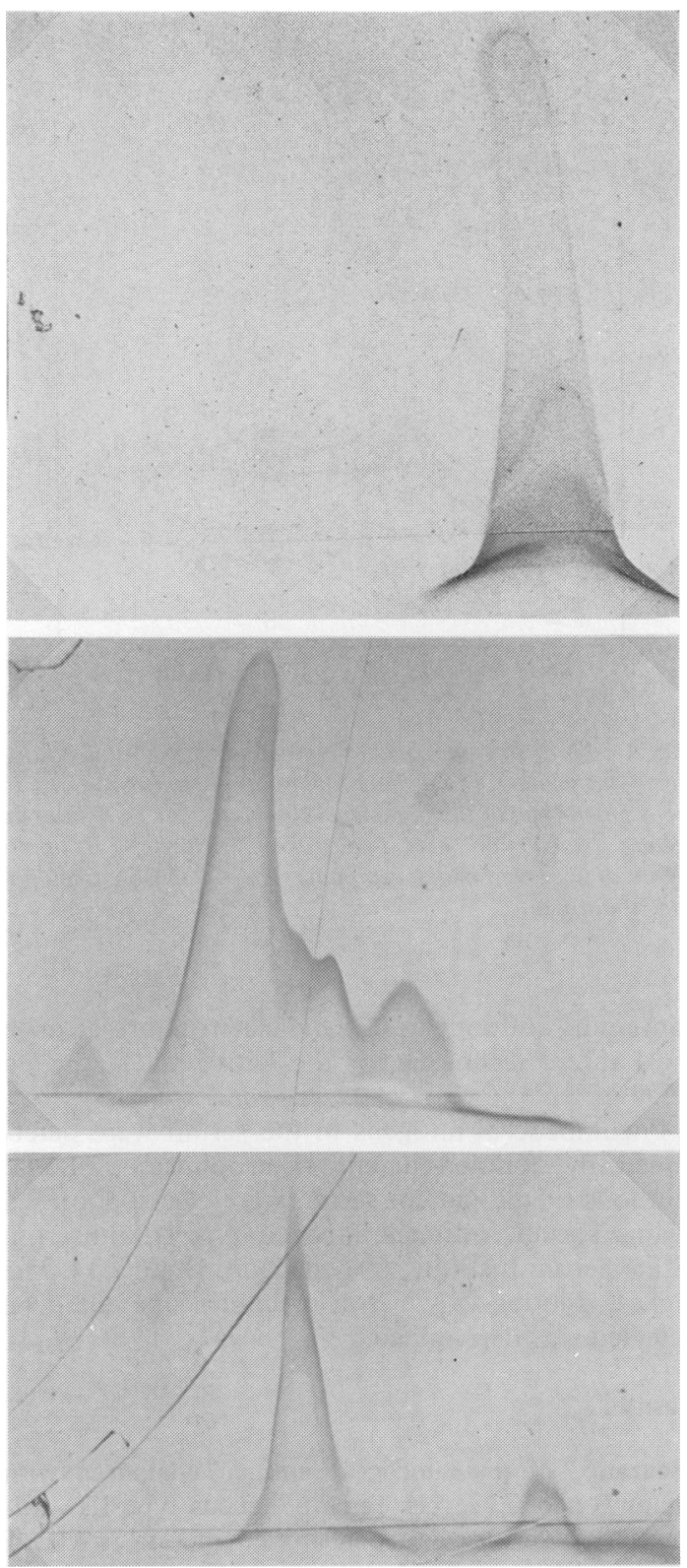

Fig. 1 Crossed immunoelectrophoresis of native or activated C3 (Laurell technique ${ }^{5}$ ). For the first dimension, the starting point is on the right, anode on the left. In the second dimension, the anode is at the top. In the top portion, native $C 3$ is defined by a single peak; in the middle portion, native $C 3$ is completely activated by antigenantibody complexes; in the bottom portion, activated $C 3$ by 24 hours' storage at $20^{\circ} \mathrm{C}$ : in the middle figure where $C 3$ is completely activated, a small peak of native $C 3$ is still visible to the right of the major peak of $\mathrm{C3}_{\text {c.. }}$.
Factor B and activated factor B $(\overline{\mathbf{B}})$ were determined by the method of Palestine and Klemperer. ${ }^{4}$ Native factor B activated by zymosan served as a control. Factor $\mathrm{B}$ and $\mathrm{C} 3$ concentrations were expressed in units, the reference standard serum being designated as 100 units. One unit of $\mathrm{C} 3$ corresponded to $0.94 \mathrm{mg} / 100 \mathrm{ml}$ of a standard serum of Behring. The ratio of native to activated C3 was determined by cross-electrophoresis as previously reported by Laurell and Lundh. ${ }^{5}$ In essence, $5 \mu \mathrm{l}$ serum was electrophoresed for 2 hours at $20 \mathrm{~V} / \mathrm{cm}$ in $1 \%$ agarose at $\mathrm{pH} 8.6,0.05 \mathrm{~mol} / \mathrm{l}$ veronal with $0.009 \mathrm{~mol} / \mathrm{l}$ calcium lactate, using a discontinuous buffer system in the buffer tank. The gel portion containing the electrophoresed serum was then cut out, transferred to another agarose plate containing antibodies to human C3 in the same buffer, and electrophoresed at $4 \mathrm{~V} / \mathrm{cm}$ for 16 hours. The dried agarose plates were stained with amido-black, the peaks were then projected and drawn on paper, cut out, and the paper weighed (Fig. 1).

C3 phenotypes were analysed according to Pflugshaupt et al. $^{6}$ Agarose gel electrophoresis at $20 \mathrm{~V} / \mathrm{cm}$ for 4 hours was performed in a $\mathrm{pH} 8.6$ veronal-lactate buffer, ionic strength 0.05 for the gel and 0.1 for the buffer tank. The agarose was then fixed in ethanol and glacial acetic acid solution, and stained with amido-black (Fig. 2).

For further quantitation of the phenotypes, the unfixed gels were cut out and placed in an agarose gel

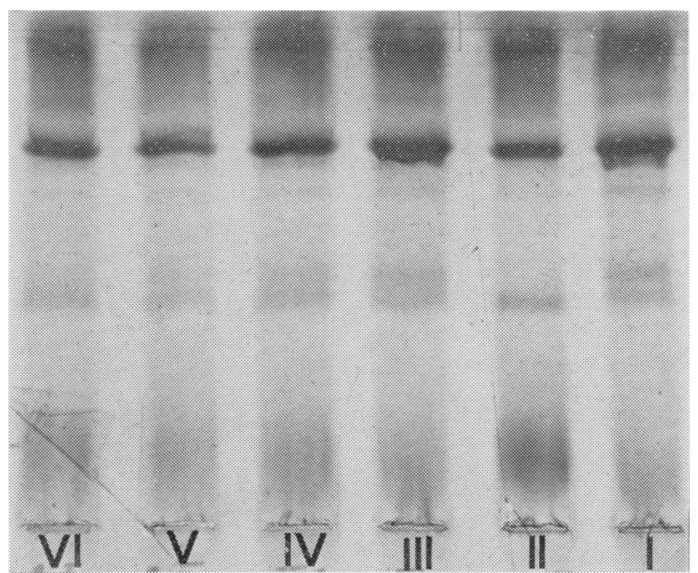

Fig. 2 Phenotypes of C3. The starting point is at the bottom, the anode at the top of the gel. Darkest line is transferrin. Phenotypes in the middle zone: (I) Donor's phenotype FS. (II) Recipient's phenotype-S. (III) End of the exchange transfusion, conversion to the phenotype of the donor FS. (IV-VI) Gradual disappearance of the F-line $90 \mathrm{~min}, 180 \mathrm{~min}$, and $330 \mathrm{~min}$ after exchange transfusion with return to phenotype $S$. 

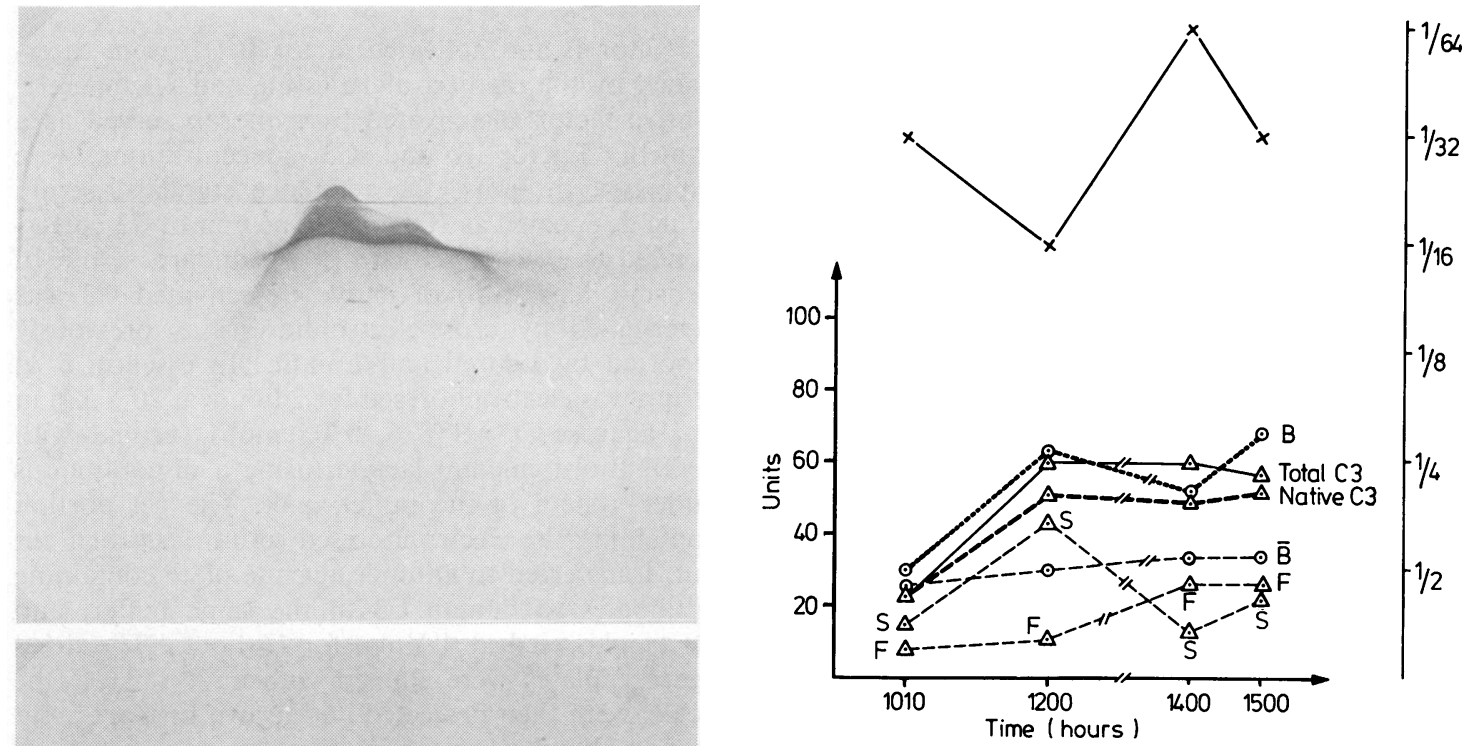

Fig. 4 Fatal pneumococcal septicaemia in a term infant. Recipient probably had the FS phenotype and converted to the S phenotype of the donor at 1200 hours. At 1400 hours a second transfusion was undertaken with an FS donor identical with that of the recipient. $\times-\times$ Free pneumococcal antigen.

containing antibody to $\mathrm{C} 3$, and electrophoresed as in the Laurell ${ }^{5}$ technique for the native and activated C3 (Fig. 3).

Pneumococcal antigens in the serum were determined by counter-current electrophoresis. ${ }^{7}$ Serial dilutions of the patient serum were electrophoresed against specific antipneumococcus type III antiserum (State Serum Institute, Copenhagan, Denmark). The highest dilution in which a precipitin line could be detected was determined.

\section{Results}

Clearance of pneumococcal antigen compared with factor B and C3 levels. Pneumococcus type III antigen serum levels were determined in one newborn infant with pneumococcal sepsis treated by antibiotics and exchange transfusion. As shown (Fig 4). pneumococcal antigen titre remained unchanged (fluctuating between $1 / 16$ and $1 / 64$ ) while factor $B$

Fig. 3 C3 phenotype quantitation. Top phenotype $F$, middle phenotype $F S$, bottom phenotype $S$; running conditions identical with Fig. 1. Running time 4 hours instead of 2 hours in the first dimension. 
and $\mathrm{C} 3$ concentrations, which were initially low, increased greatly after transfusion. Moreover, C3 phenotypes switched from the recipient's to the donor's.

Alpha-1-antitrypsin. Alpha-1-antitrypsin levels in acid citrate dextrose diluted plasma were $1 \mathrm{P} 72 \mathrm{~g} / 1 \pm 0 \mathrm{P} 04$ (1 SD) SD (about $20 \%$ lower than in undiluted plasma). After the transfusion, in all instances $\mathrm{K}-1$-antitrypsin levels remained unchanged or, as

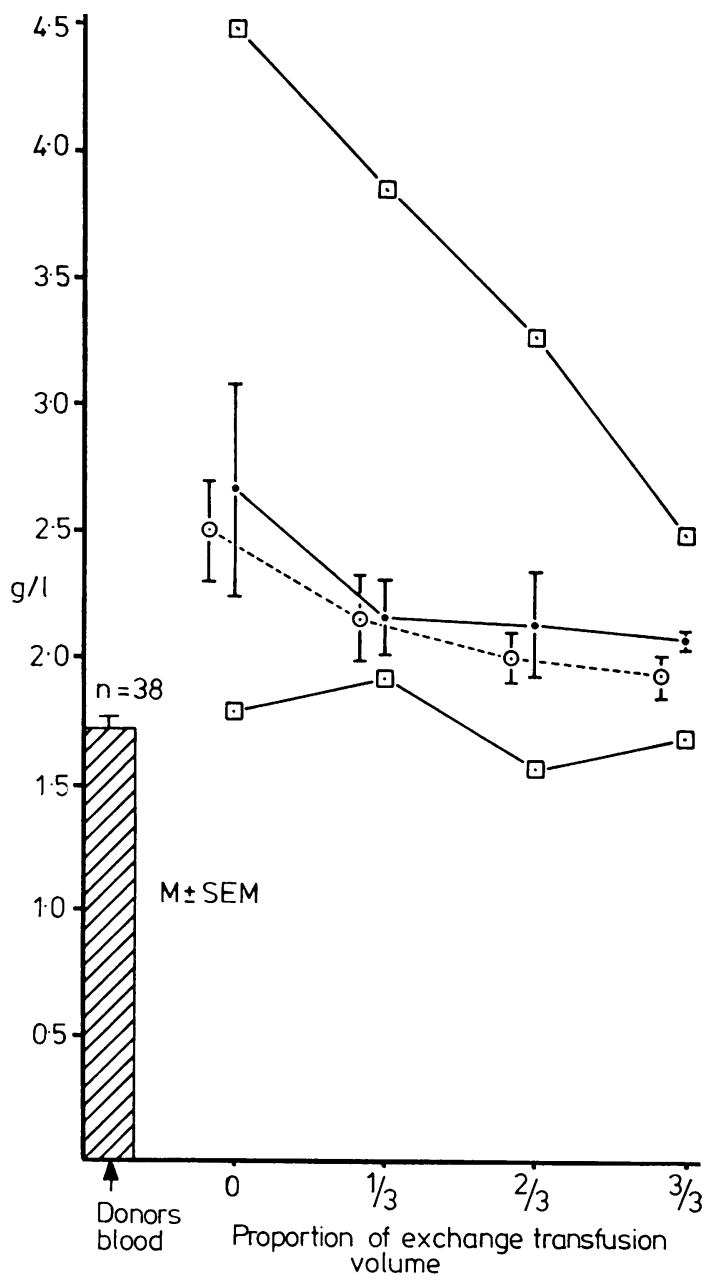

Fig. 5 Alpha-1-antitrypsin concentration during exchange transfusions in newborn infants as follows:

$\square-\square$ E. coli septicaemia and sclerema.

-_ Suspected infections.

$\odot---\odot$ Hyperbilirubinaemia $X$ or $R h$ or $A B O$

incompatibility.

Note the fall in the concentration of the protein with adaptation to donor's level. might be expected, decreased to the donor plasma level (Fig. 5) .Before the transfusion, no decrease of $\mathrm{K}-1$-antitrypsin was noted, so excluding a kinin inhibitor deficit in neonatal sepsis with sclerema.

Factor B. The decrease in factor B levels was related to the severity of the disease. Fatal sepsis with sclerema (Fig. 6) was associated with the lowest levels of this factor $(26 \mathrm{P} 3 \pm 0 \mathrm{P} 9$ units). In blood group incompatibility and hyperbilirubinaemia, the initially normal level of factor B ( $89 \pm 6$ units) was generally unchanged by the transfusion. However in septic newborn babies with low factor B $(62 \pm 10 \cdot 2$ units), at least 3 exchange transfusions were required to increase the levels. Three out of 11 septic infants died despite the correction of factor B levels by transfusion (Fig. 7).

Activated factor B $(\bar{B})$ was detected only in the patient with pneumococcal sepsis, and it was not eliminated by transfusion.

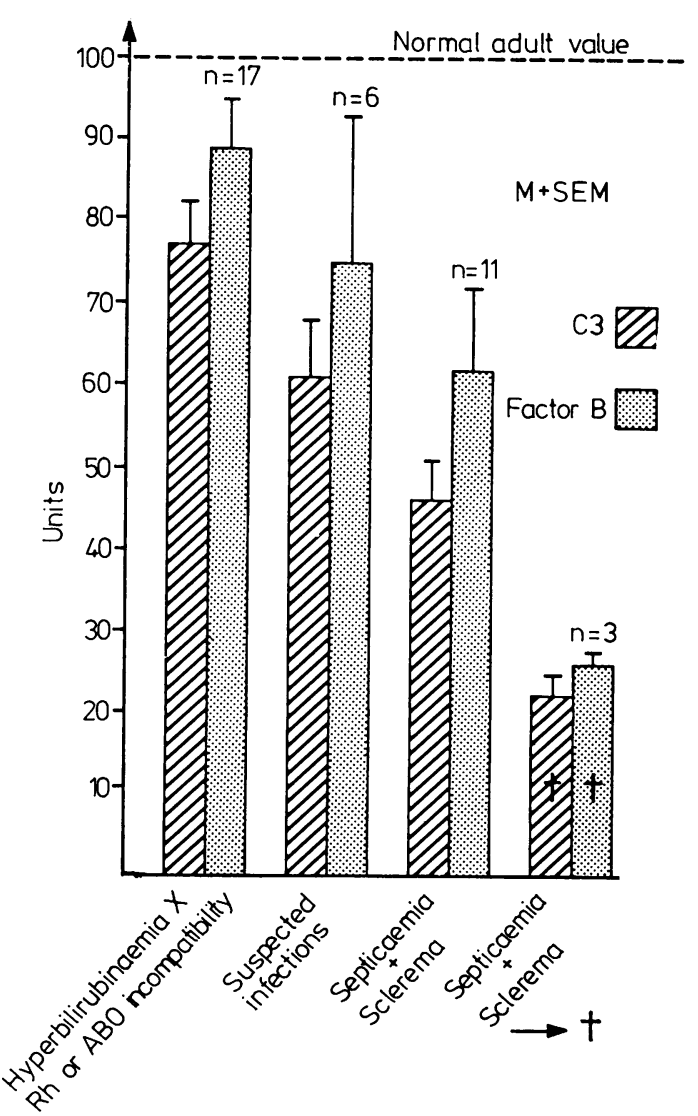

Fig. 6 Factor $B$ and $C 3$ concentration before first exchange transfusion. 
C3. The lowest $\mathrm{C} 3$ levels were seen in fatal sepsis and sclerema $(22 \cdot 3 \pm 2 \cdot 4$ units), while normal values were recorded in hyperbilirubinaemia of unknown origin and in $\mathrm{ABO}$ or $\mathrm{Rh}$ incompatibility $(78 \pm 4.4$ units) (Fig. 6). In septic newborn infants, $\mathrm{C} 3$ levels increased only transiently after transfusion (to about two-thirds of the donor levels) and returned 4 hours later to the initial low value $(55 \cdot 7 \pm 7 \cdot 6$ units, 12 hours after transfusion compared with $46 \cdot 1 \pm 5 \cdot 8$ units before) (Fig. 7).

By using the Laurell ${ }^{5}$ technique, an antiserum reacting with native $\mathrm{C} 3$ as well as with its breakdown products, we noted both components in the serum (Fig. 1). However, compared with 19 donors in whom the level of $\mathrm{C} 3$ breakdown products was less than $2 \%$ of the total $\mathrm{C} 3$, much higher levels were recorded in only 2 out of 11 septicaemic newborn babies. In one, only $39 \%$ of the total $\mathrm{C} 3$ was in the native form $\left(61 \%\right.$ was in the form of $\left.C 3_{c}\right)$. This patient had raised levels of $\alpha$-1-antitrypsin, indicating that the low $\mathrm{C} 3$ levels were not due to lack of proteolytic inhibitory factor.

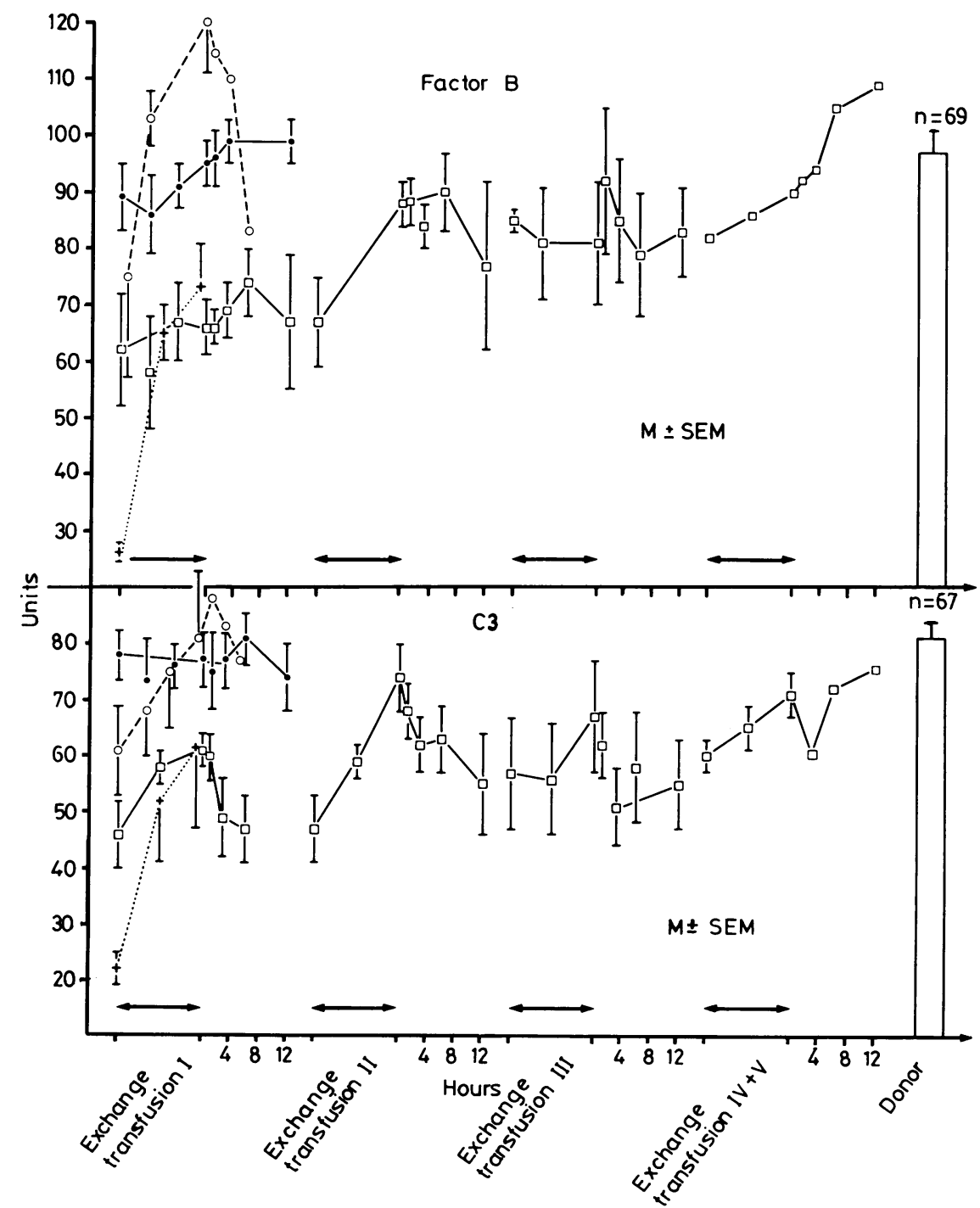

Fig. 7 Factor $B$ and C3 concentration during and after exchange transfusion. •-_ Hyperbilirubinaemia of unknown origin and $\mathrm{Rh}$ or $\mathrm{ABO}$ incompatibility. $\mathrm{O}_{---}-\mathrm{O}$ Suspected infections. $+\cdots \cdots+$ Last transfusion in fatal septicaemia. 


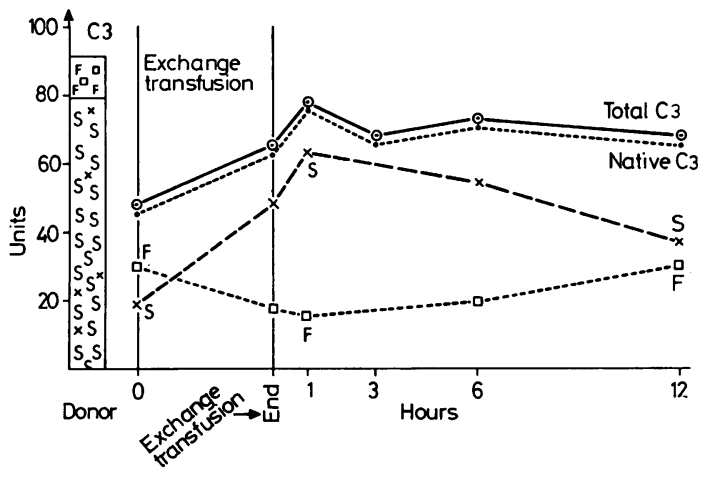

Fig. 8 Total $C 3 \odot-\odot-\odot$ and native C3 level ..... during transfusion and quantitative determinations of the different phenotypes $\square---\square F \times----\times S$ during and after transfusion in a newborn with $K$. pneumoniae, septicaemia, and sclerema.

Phenotypes of C3. C3 phenotypes (FS, F, and S) were studied before and after 56 exchange transfusions. In $19(34 \%)$ transfusions there was a difference in phenotypes between donor and recipient. In all these patients the phenotype of the recipient converted to that of the donor after the transfusion (Figs 2 and 8). The synthesis or consumption of $\mathrm{C} 3$ was calculated by multiplying the plus or minus change in the respective C3 phenotype plasma concentration per hour, with the total plasma volume, divided by the weight in $\mathrm{kg}$ (plasma volume was assumed to be $6 \%$ of body weight). As synthetised C3 is subjected to the same consumption as the transfused $\mathrm{C} 3$, the calculated $\mathrm{C} 3$ consumption was added to the calculated synthesis to obtain the actual synthesis. $\mathrm{C} 3$ levels and phenotypes were studied in 3 patients with $\mathrm{Rh}$ or ABO incompatibility over 6 periods of time, and in 3 septic newborn babies with sclerema or suspected infection over 7 periods of time after exchange transfusion. Quantitation of phenotypes showed that transfused C3 reached equilibrium 4 hours after transfusion (Fig. 8). Our results indicate that the rate of $\mathrm{C} 3$ synthesis in all these infants was three times higher than in normal adults or in systemic lupus erythematosus using radiolabelled $\mathrm{C} 3 .^{8}$ There was no significant difference in $\mathrm{C} 3$ consumption between septic and nonseptic infants who had had transfusions.

\section{Discussion}

Various parts of the immune system have been shown to be poorly developed in the normal newborn infant, and these immunological deficits may be the reason for the poor prognosis of neonatal sepsis compared with septicaemia in an older infant. This has, for example, been well documented in streptococcal infection, where newborn infants of mothers lacking specific streptococcal antibodies that could be transferred to them through the placenta were more prone to such infections. ${ }^{9}$ Opsonic defects have also been reported in such newborn infants. It is unlikely that the lack of specific antibodies is the sole cause of the opsonic defect in the newborn. Several other factors have been implicated, including defects in the complement system. Previously we reported that the opsonic defect in neonatal septicaemia could be reversed in vitro by incubating the infant's granulocytes with normal adult serum. ${ }^{1}$ In this study we investigated the integrity of the major and alternate complement pathways in septic and nonseptic newborn infants. We also evaluated the in vivo effects of exchange transfusions on the complement pathways. Low levels of $\mathrm{C} 3$ and factor $\mathrm{B}$ were noted in all septicaemic newborn infants with sclerema; after 3 or more transfusions, these factors were corrected and have remained stable. These findings raise the question whether the initial low level of complement components was due to decreased synthesis, or to increased consumption. Increased consumption could occur in the event of antikinin deficiency-such as $\alpha$-1-antitrypsin-but we could not demonstrate such an $\alpha$-1-antitrypsin deficit. Moreover, in adult sepsis, low levels of factor B are generally accompanied by the appearance of activated products of this factor, suggesting increased catabolism. ${ }^{411}$ We were unable to detect in the hypocomplementaemic septic newborn either factor $\overline{\mathrm{B}}$ or $\mathrm{C} 3$ breakdown products. In addition, the complement consumption rate of donor's $\mathrm{C} 3$ and factor B was not increased in neonatal sepsis compared with newborn infants with $\mathrm{ABO}$ or $\mathrm{Rh}$ incompatibility (Fig. 9). A slow rate of synthesis might therefore be responsible for the hypocomplementaemia. However, calculation of $\mathrm{C} 3$ synthesis using the reappearance of recipients' phenotype after transfusion, suggested rather an increased rate of synthesis. In the light of these findings, the recorded low C3 levels (Fig. 6) might have been attributable to an abnormal distribution of $\mathrm{C} 3$ in a larger extravascular fluid compartment. This assumption is supported by the frequent appearance of sclerema in the septic newborn.

Our failure to document the presence of activated factor $\overline{\mathrm{B}}$ and $\mathrm{C} 3$ breakdown products, indicates that the abnormal opsonisation in the newborn may be linked to defective activation of the complement pathways, as has been reported by Adamkin et al. ${ }^{10}$

These findings show that exchange transfusion 


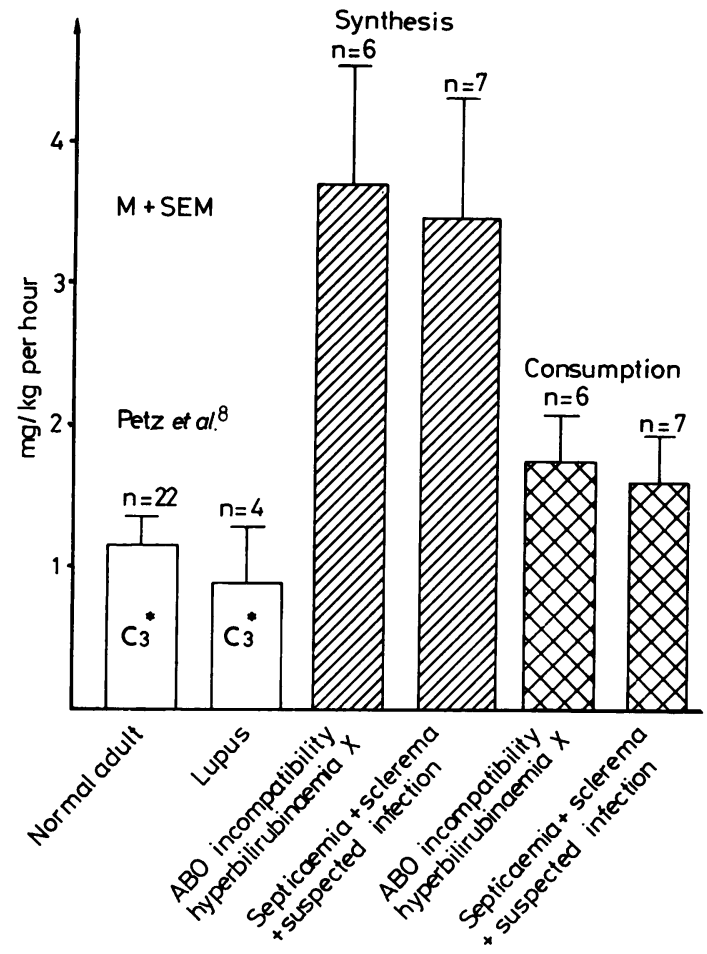

Fig. 9 Synthesis and consumption of $\mathrm{C} 3$ in newborn infants.

may be viewed as an extremely effective source of opsonins, including not only specific antibodies but also C3 and factor B in a form which could be activated. Transfusion of fresh plasma might well be superior to blood. Our studies show that very large volumes of blood are needed to correct complement deficits in the newborn; this requires plasmapheresis or exchange transfusion.

I thank Professor A Rubinstein, Department of Cell Biology, Albert Einstein College of Medicine, New York, for much advice.

\section{References}

1 Pelet B. Exchange transfusion in newborn infants: effects on granulocyte function. Arch Dis Child 1979; 54: 687-90.

2 Mancini G, Vaerman J P, Carbonara A O, Heremans J F. A single radial diffusion method for the immunological quantitation of proteins. In: Peeters $\mathrm{H}$, ed. Protides of the biological fluids. Proceedings of the Eleventh Colloquium, Bruges, 1963. Amsterdam: Elsevier, 1964: 370-3.

3 Alper C A, Rosen F S. Complement in laboratory medicine. In: Vyas G N, Stites D P, Brecher G, eds. Laboratory diagnosis of immunologic disorders. New York: Grune \& Stratton, 1975: 47-68.

4 Palestine A G, Klemperer $M$ R. In vivo activation of properdin factor $\mathbf{B}$ in normotensive bacteremic individuals. J Immunol 1976; 117: 703-5.

${ }^{5}$ Laurell C B, Lundh B. Electrophoretic studies of the conversion products of serum $\beta$ 1c-globulin. Immunology 1967; 12: 313-9.

${ }^{6}$ Pflugshaupt R, Scherz R, Steinegger L, Bütler R. The frequency of the polymorphisms of $\mathrm{C}_{3}$ in the Swiss population, and some remarks on the identification of rare phenotypes. In: Peeters $\mathrm{H}$, ed. Protides of the biological fluids. Proceedings of the Twenty-second Colloquium, Bruges, 1974. Oxford: Pergamon Press, 1975: 559-62.

7 Greenwood B M, Whittle H C, Duminic-Raykovic O. Countercurrent immunoelectrophoresis in the diagnosis of meningococcal infections. Lancet 1971; ii: 519-21.

8 Petz L D, Cooper N R, Powers R, Fries J. The metabolism of radiolabelled $\mathrm{C}_{3}\left({ }^{125} \mathrm{I}-\mathrm{C}_{3}\right)$ in autoimmune disorders. In: Peeters H, ed. Protides of the biological fluids. Proceedings of the Twenty-second Colloquium, Bruges, 1974. Oxford: Pergamon Press, 1975: 547-50.

9 Zimmerman R A, Hill H R. Placental transfer of group A type-specific streptococcal antibody. Pediatrics 1969; 43: 809-14.

10 Adamkin D, Stitzel A, Urmson J, Farnett M L, Post E, Spitzer R. Activity of the alternative pathway of complement in the newborn infant. J Pediatr 1978; 93: 604-8.

11 Fearon D T, Ruddy S, Schur P H, McCabe W R. Activation of the properdine pathway of complement in patients with Gram-negative bacteremia. $N$ Engl J Med 1975; 292 : 937-40.

Correspondence to Dr B Pelet, Service de Pédiatrie, Clinique Infantile, Centre Hospitalier Universitaire Vaudois, 1011 Lausanne, Switzerland.

Received 5 June 1979 